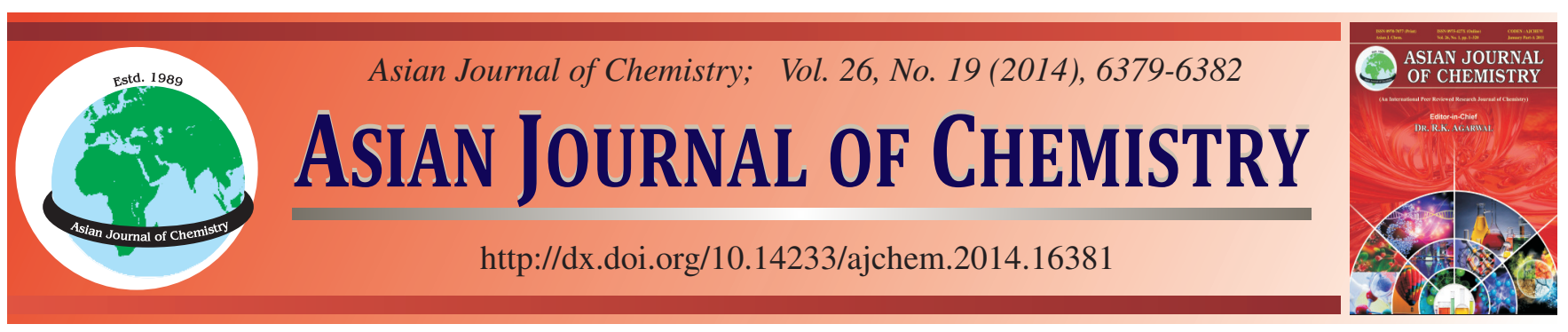

\title{
Simple Preparation of Components from Gardenia Jasminoides Ellis by Targeted Partition in Liquid Two-Phase Extraction
}

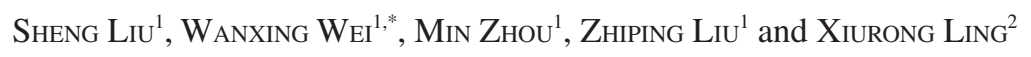

${ }^{1}$ Department of Chemistry, Guangxi University, Nanning 530004, Guangxi Province, P.R. China

${ }^{2}$ Department of Environment, Guangxi University, Nanning 530004, Guangxi Province, P.R. China

*Corresponding author: Fax: +86 771 3272601; Tel: +86 771 3233718; E-mail: wxwei@ gxu.edu.cn

Received: 16 September 2013; $\quad$ Accepted: 28 February 2014; $\quad$ Published online: 16 September 2014; $\quad$ AJC-15921

\begin{abstract}
Compounds were prepared from Gardenia jasminoides Ellis by targeted partition in two-liquid phase system without any chromatography columns. After Gardenia yellow and target guide reagent (polyethylene glycol, PEG) are dissolved in water, they would be partitioned with organic solvents in gradient to selectively give high-richened target component fractions. These fractions were crystallized, respectively to provide three components. Two of them were crocetin [ $\beta$-D-glucopyranosyl-(1-6)- $\beta$-D-glucopyranosyl] ester (1) and crocin (2). Effects of partition on targeted compounds were investigated. The results not only shows that the component which is more oleophilic was most difficult to be extracted from the organic phase in these targeted partition systems, but also shows that using the target indicator PEG2000 , which is the lowest molecular weight in these systems, can facilitate selective separation of components.
\end{abstract}

Keywords: Gardenia yellow, Targeted partition, Crocetin ester, Polyethylene glycol, Preparation.

\section{INTRODUCTION}

Gardenia jasminoides Ellis belongs to Rubiaceae family and used as traditional herb in China because its analgesic, fybrolytic, antiphlogistic, homeostatic and antipyretic affect can last for a long time ${ }^{1,2}$. Gardenia yellow pigment is extracted from Gardenia fruit, which is normally was used as food additive and colorants for textiles and especially for food, e.g., noodles and sweets. Gardenia yellow pigment is highly desirable to make the identification of these carotenoids; thus it can demonstrate the different color of these fruits based on the presence of carotenoids, $\alpha$-crocin and crocetin derivatives, which are about $4.5 \mathrm{mg} / \mathrm{g}$ in dry gardenia fruit ${ }^{3,4}$. Crocin and crocetin have been reported that they have some pharmacological effectiveness, such as treating transient global cerebral ischemia $^{5}$, antiinflammatory ${ }^{6,7}$, antioxidation ${ }^{8-10}$, hypolipidemic effect $^{11}$ and anticancer ${ }^{12,13}$.

In decades, some articles reported that preparations of crocin and other crocetin derivatives from Gardenia jasminoides or gardenia yellow were based on traditional isolation methods, such as silica gel column chromatography ${ }^{14}$, macroporous resin adsorption $^{15-17}$, membrane separation ${ }^{18}$, high-speed countercurrent chromatography (HSCCC) ${ }^{19}$ and molecularly imprinted polymer solid-phase extraction ${ }^{20}$. Silica gel column, HPLC and HSCCC can provide pure compounds, but those approaches cannot be applied in large-scale preparation because of the problems on small amount of yield, time-consuming, expensive and complex equipments. Using the approaches based on macroporous resin adsorption and membrane separation may provide huge amount products but in low purity quotient. Because of bioactivities of the crocin and other crocitin derivatives, a simple and effective method for large-scale preparation of pure products, may be developed.

In this study, a simple and effective method, which is to separate crocin and another crocitin derivative in large scale on basis of targeted partition in two-phase liquid system without any chromatography columns, will be developed. After the experiment the result not only shows that soluble polymer solutions acts as target guide reagent and made partition have selectivity; but also shows that there are (different) effects of target guide reagent PEG in different molecular weight, on separation of crocin and another crocetin derivative.

\section{EXPERIMENTAL}

Analytical-grade petroleum ether (PE, b.p. $60-90{ }^{\circ} \mathrm{C}$ ), ethyl acetate (EA), methanol $(\mathrm{MeOH}), n$-butanol were obtained from Xilong Chemical Co. Ltd. (Guangdong, China). All chemicals were in analytical grade. Water was of distilled water. Polyethylene glycol (PEG) 2000, 4000, 6000, 10000, 20000 were obtained from Guanghua Chemical Co. Ltd. (Guangdong, China). The materials of HPLC analysis was of chromatographic grade and purchased from Xi Long Chemical Industry 
Company (Guangdong, China). Shanyun Biochemical Co., Ltd. (Guangxi, China) supplied gardenia yellow pigment.

General procedure: $5 \mathrm{~g}$ Gardenia yellow pigment sample was extracted with $\mathrm{MeOH}(3 \times 100 \mathrm{~mL})$ for $10 \mathrm{~min}$ assisted by ultrasonic assistance repeatedly. The extracts were combined and filtered, then was condensed to obtain a dry residue (4.35 $\mathrm{g})$. This residue and $1.5 \mathrm{~g}$ PEG-6000 were dissolved in $150 \mathrm{~mL}$ water and then was extracted with PE repeatedly $(3 \times 150 \mathrm{~mL})$. Then heavy phase, the aqueous solution, was extracted with ethyl acetate repeatedly $(3 \times 150 \mathrm{~mL})$. The light phase, ethyl acetate extracts, were then combined and evaporated to obtain compound 1 ( $0.46 \mathrm{~g}, 94.7 \%)$. After extracted by ethyl acetate, the aqueous phase was evaporated to obtain a liquid dry residue, then was dispersed in a mixture solvent (Ethyl acetate:MeOH $=3: 1, \mathrm{v} / \mathrm{v})$, then were filtered to give filtrate and a filter cake. The filter cake was washed with ethyl acetate-MeOH mixture solvent (Ethyl acetate: $\mathrm{MeOH}=3: 1, \mathrm{v} / \mathrm{v}$ ) repeatedly and then was dissolved in $50 \mathrm{~mL}$ water. In the next, the aqueous solution was extracted with solvent $(50 \mathrm{~mL} \times 3$, ethyl acetate-butanol, $3: 2$, v/v) repeatedly. After that, the light phase was evaporated to obtain a dry residue. Later the residue was dissolved in $10 \mathrm{~mL}$ ethyl acetate-methanol system (ethyl acetate: methanol $=4: 1$, $\mathrm{v} / \mathrm{v}$ ) with ultrasonic assistant at $45^{\circ} \mathrm{C}$ and kept at room temperature over night to obtain yellow needle crystal (compound $2,1.57 \mathrm{~g}, 95.1 \%$ ). The processes is presented in Fig. 1.

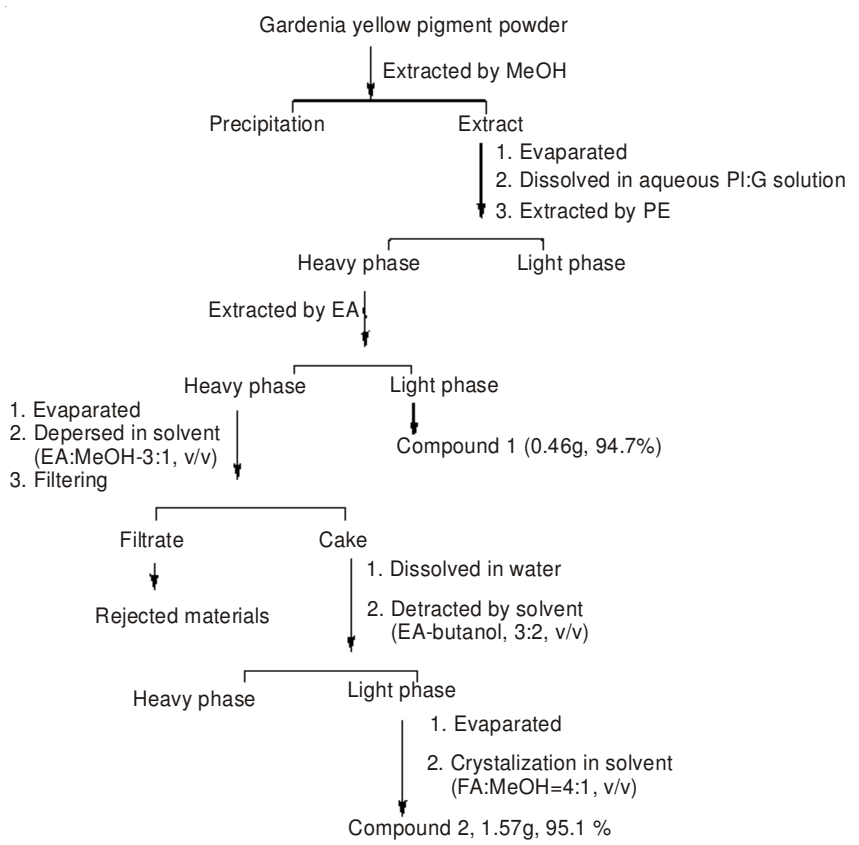

Fig. 1. Operation scheme of separations

Detection method: Analysis was performed in an Agilent HPLC 1100 series with a reverse column (Agilent C18, 4.6× $250 \mathrm{~mm}, 5 \mu \mathrm{m})$. Mobile phases were consisted of water and methanol; a linear gradient (53-60\% methanol in 10 min, $60 \%$ methanol for $8 \mathrm{~min}, 60-85 \%$ methanol in $7 \mathrm{~min}, 85 \% \mathrm{~B}$ for $20 \mathrm{~min}$ ) was applied in flow rate $1 \mathrm{~mL} / \mathrm{min}$; injection volume was $5 \mu \mathrm{L}$ and detection was performed at wavelength of 440 $\mathrm{nm}$. All the samples were filtered with a $0.45 \mu \mathrm{m}$ micro filter. The retention times of compound $\mathbf{1}$ and $\mathbf{2}$ and the impurity were 7.70, 10 and $34.80 \mathrm{~min}$, respectively.
Compound 1: Reddish-yellow powder, m.p. $206.2{ }^{\circ} \mathrm{C}$, $\mathrm{UV} \lambda_{\max }(\mathrm{MeOH}) \mathrm{nm}(\log \varepsilon): 430$ (4.16). ESI-MS $\mathrm{m} / z$ (rel. int.): $675.2607(\mathrm{M}+\mathrm{Na}), 619.2361$ (56), 593.2198 (82). IR: $3413 \mathrm{~cm}^{-1}(\mathrm{OH}), 2922(\mathrm{CH}), 1702(\mathrm{C}=\mathrm{O}), 1613,1568(\mathrm{C}=\mathrm{C})$, 1075 (C-O). ${ }^{1} \mathrm{H}$ NMR (DMSO- $\left.d_{6}, 600 \mathrm{MHz}\right) \delta 1.95$ [each $3 \mathrm{H}$, $\left.\mathrm{s},\left(\mathrm{CH}_{3}\right)_{4}\right], 2.50\left(2 \mathrm{H}, \mathrm{dd}, J=4.8,4.8 \mathrm{~Hz}, \mathrm{C} 2{ }^{\prime \prime}-\mathrm{H}\right), 2.95-3.45$ (m, other proton signals of sugar), 3.96-4.20 (2H, m, C-6", 6"'-H), 5.40 (1H, d, J = 9 Hz, C1"'-H), 5.42 (1H, d, $J=9$ Hz, C1"-H), 6.48 (1H, dd, $J=11,1 \mathrm{~Hz}, \mathrm{C} 14-\mathrm{H}), 6.51$ (1H, dd, $J=$ 11.5, $\left.1 \mathrm{~Hz}, \mathrm{C} 14^{\prime}-\mathrm{H}\right), 6.53$ (1H, dd, $\left.J=7.2,5 \mathrm{~Hz}, \mathrm{C} 12^{\prime}-\mathrm{H}\right)$, $6.60(1 \mathrm{H}, \mathrm{dd}, J=7.2,5 \mathrm{~Hz}, \mathrm{C} 11-\mathrm{H}), 6.62(1 \mathrm{H}, \mathrm{dd}, J=7.6,5.2$ $\left.\mathrm{Hz}, \mathrm{C} 11^{\prime}-\mathrm{H}\right), 6.68$ (1H, dd, $\left.J=15.4,5 \mathrm{~Hz}, \mathrm{C} 15^{\prime}-\mathrm{H}\right), 6.82(1 \mathrm{H}$, $\mathrm{d}, J=5 \mathrm{~Hz}, \mathrm{C} 12-\mathrm{H}), 6.83(1 \mathrm{H}, \mathrm{dd}, J=15.4,5 \mathrm{~Hz}, \mathrm{C} 15-\mathrm{H})$, 7.19 (1H, d, $\left.J=11 \mathrm{~Hz}, \mathrm{C} 10^{\prime}-\mathrm{H}\right), 7.35(1 \mathrm{H}, \mathrm{d}, J=11.5 \mathrm{~Hz}$, C10-H), ${ }^{13} \mathrm{C}$ NMR (DMSO- $\left.d_{6}, 150 \mathrm{MHz}\right) \delta: 166.3,169.1(8$, 8'-C), 124.5, 125.2 (9, 9'-C), 140, 137 (10, 10'-C), 124.5, 123.8 (11, 11'-C), 144.8, 142.9 (12, 12'-C), 136.6, 136.2 (13, 13'C), 136, 135.2 (14, 14'-C), 132.2, 131.5 (15, 15'-C), 12.7, 12.6 (19, 19'-C), 13, 12.8 (20, 20'-C), 94.6 (1"-C), 103.1 (1"'-C), 73.5 (2"-C), 72.5 (2"'-C), 76.9 (3, 3'-C), 69.3 (4"-C), 69.9 (4"'C), 76.8 (5"-C), 76.3 (5"'-C), 68 (4"-C), 61 (4"'-C).

Compound 2: Reddish-yellow crystal, m.p. $215.2^{\circ} \mathrm{C}, \mathrm{UV}$ $\lambda_{\max }(\mathrm{MeOH}) \mathrm{nm}(\log \varepsilon): 435$ (5.16). ESI-MS $m / z$ (rel. int.): $999.3660(\mathrm{M}+\mathrm{Na}), 511.1785$ (488). IR: $3428 \mathrm{~cm}^{-1}(\mathrm{OH}), 2922$ (CH), $1696(\mathrm{C}=\mathrm{O}), 1568,1413(\mathrm{C}=\mathrm{C}), 1068(\mathrm{C}-\mathrm{O}) .{ }^{1} \mathrm{H}$ NMR (DMSO- $\left.d_{6}, 600 \mathrm{MHz}\right) \delta 1.96,1.99\left[\right.$ each $\left.3 \mathrm{H}, \mathrm{s},\left(\mathrm{CH}_{3}\right)_{4}\right], 2.96$ (2H, dd, $J=4.8,4.8 \mathrm{~Hz}, \mathrm{C} 2$ '"-H), 2.95-3.42 (m, other proton signals of sugar), 3.57-3.64 (2H, m, C-6", 6"'-H), 4.17 (2H, d, $J=8 \mathrm{~Hz}, \mathrm{C} 1$ "'-H), $5.41(2 \mathrm{H}, \mathrm{d}, J=7.6 \mathrm{~Hz}, \mathrm{C} 1 "-\mathrm{H}), 6.66(2 \mathrm{H}$, $\mathrm{dd}, J=8,2.5 \mathrm{~Hz}, \mathrm{C} 14,14 '-\mathrm{H}), 6.80$ (2H, dd, $J=11.6 \mathrm{~Hz}, \mathrm{C} 11$, $\left.11^{\prime}-\mathrm{H}\right), 6.82$ (2H, d, $\left.J=15.2 \mathrm{~Hz}, \mathrm{C} 12,12^{\prime}-\mathrm{H}\right), 6.85$ (2H, dd, $J$ $\left.=8,2.8 \mathrm{~Hz}, \mathrm{C} 15,15^{\prime}-\mathrm{H}\right), 7.34$ (2H, d, $J=10.4$ Hz, C10, 10'-<smiles>CC(C=CC=C(C)C(=O)O)=CC=CC=C(C)C=CC=C(C)C(=O)OC1O[C@H](CO[C@H]2O[C@H](CO)[C@@H](O)[C@H](O)[C@H]2O)[C@H](O)[C@H](O)[C@H]1O</smilesMol. Wt.: 652.68

Structural of compound 1

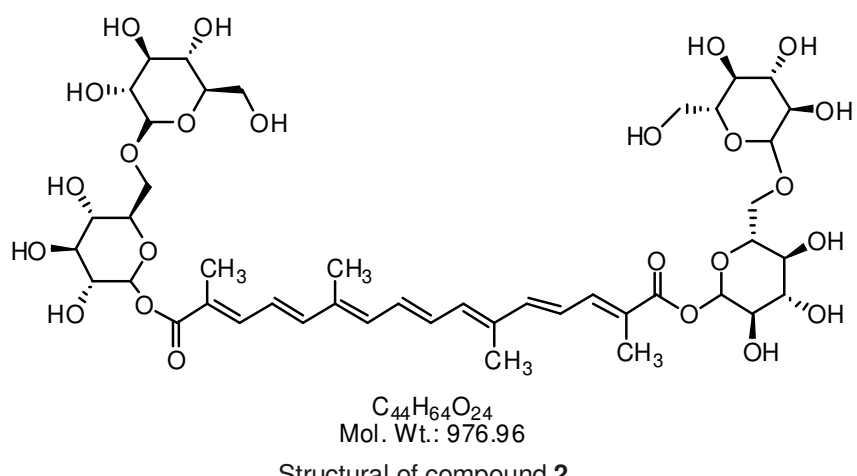

Structural of compound 2 
H), ${ }^{13} \mathrm{C}$ NMR (DMSO- $\left.d_{6}, 150 \mathrm{MHz}\right) \delta: 166.3\left(8,8^{\prime}-\mathrm{C}\right), 125.3$ (9,9'-C), 140 (10, 10'-C), 123.9 (11, 11'-C), 144.7 (12, 12'-C), 137 (13, 13'-C), 136 (14, 14'-C), 132 (15, 15'-C), 12.6 (19, 19'-C), 12.7 (20, 20'-C), 94.6 (1"-C), 103.1 (1"'-C), 72.5 (2"C), 73.5 (2'"-C), 76.8 (3, 3'-C), 69.2 (4"-C), 69.3 (4"'-C), 76.8 (5"-C), 76.3 (5"'-C), 67.9 (4"-C), 61.0 (4"'-C).

\section{RESULTS AND DISCUSSION}

Extraction ratio (E) was used to indicate efficiency of targeted partition. It was presented as following equation:

$$
\mathrm{E}=\mathrm{A}_{\mathrm{o}} / \mathrm{A}_{\mathrm{s}}
$$

where $A_{o}$ was the relative concentration of components in organic phase and $A_{s}$ was the relative concentration in the starting solution $\left[\mathrm{A}_{\mathrm{o}}\right.$ and $\mathrm{A}_{\mathrm{s}}$ were obtained as signal data (peak area) from HPLC].

A ratio of component in two phases, partition coefficient (K) was showed as following equation:

$$
\mathrm{K}=\mathrm{P}_{\mathrm{o}} / \mathrm{P}_{\mathrm{w}}
$$

where $\mathrm{P}_{\mathrm{o}}$ was the relative concentration of component in organic phase and $\mathrm{P}_{\mathrm{w}}$ was the relative concentration in the water phase $\left(\mathrm{P}_{\mathrm{o}}\right.$ and $\mathrm{P}_{\mathrm{w}}$ were obtained as signal data (peak area) from HPLC).

Structure elucidation: Compound 1 was isolated as reddishyellow powder. Molecular formula of compound 1 was established as $\mathrm{C}_{32} \mathrm{H}_{44} \mathrm{O}_{14}$ on base of MS, NMR and other spectroscopy data. NMR data has presented the existence of a disaccharide moiety $(\delta \mathrm{C} 61.0-103.1 ; \delta \mathrm{H} 2.95-3.42,5.41)$, a conjugated polyene moiety ( $\delta \mathrm{C} 124.5-144.8 ; \delta \mathrm{H} 6.51-7.35)$, 4 methyl groups ( $\delta$ C $12.6-13 ; \delta$ H $1.90-2.01)$ and two conjugated carbonyl carbons ( $\delta$ C 166.3 and 169.1$)$. The ${ }^{1} \mathrm{H}$ NMR, ${ }^{13} \mathrm{C}$ NMR data and other physical properties of compound $\mathbf{1}$ coincided with crocin- $3^{21-24}$, so compound $\mathbf{1}$ was confirmed as crocetin [ $\beta$-D-glucopyranosyl-(1-6)- $\beta$-D-glucopyranosyl] ester. Compound $\mathbf{2}$ was isolated as reddish-yellow crystal. Molecular formula of compound 2 established as $\mathrm{C}_{44} \mathrm{H}_{64} \mathrm{O}_{24}$ on base of MS, NMR and other spectroscopy data. The ${ }^{1} \mathrm{H}$ $\mathrm{NMR}$ and ${ }^{13} \mathrm{C}$ NMR spectra presents the existence of a disaccharide moiety ( $\delta \mathrm{C} 61-103.1 ; \delta \mathrm{H} 2.95-3.45,5.4)$, a conjugated polyene moiety ( $\delta \mathrm{C} 123.9-144.7 ; \delta \mathrm{H} 6.66-7.34), 4$ methyl groups $(\delta \mathrm{C} 12.6-12.7 ; \delta \mathrm{H} 1.95-2.20)$ and two conjugated carbonyl carbons $(\delta \mathrm{C} 166.3)$. Other ${ }^{1} \mathrm{H}$ NMR, ${ }^{13} \mathrm{C}$ NMR data and properties of compound $\mathbf{2}$ coincided with $\operatorname{crocin}^{23,24}$, so compound 2 was confirmed as crocetin [ $\beta$-D-glucopyranosyl(1-6)- $\beta$-D-glucopyranosyl] diester.

Effects of molecular weight of PEG on selectivity of extraction: At conditions that amount of sample and the amout of polymers are the same, light phase and heavy phase volume, extraction time), PEG2000, 4000, 6000, 10000, 20000 were selected respectively to investigate selectivity (selective ability) of targeted partition.

When partition was in equilibrium state, extraction ratio (E) of compound 1 in control test (extraction without any PEG) was 0.52 and its partition coefficient $\mathrm{K} 1.15$, meanwhile $\mathrm{E}$ were 0.88 and $0.63, \mathrm{~K}$ were 1.77 and 1.71 for extraction in PEG-2000 and PEG-4000 system, respectively. Results showed that, when PEGs were used in partition systems, compound 1 was easier to be extracted into organic phase. In control test, partition coefficient $\mathrm{K} 1.15$ of compound 1 revealed that this extraction was less selective and less yield. Polyethylene glycol in water phase drove compound $\mathbf{1}$ into organic phase and make the extraction to be more selective. Meanwhile a less molecular weight PEG (PEG-2000) led a better outcome (Fig. 2).

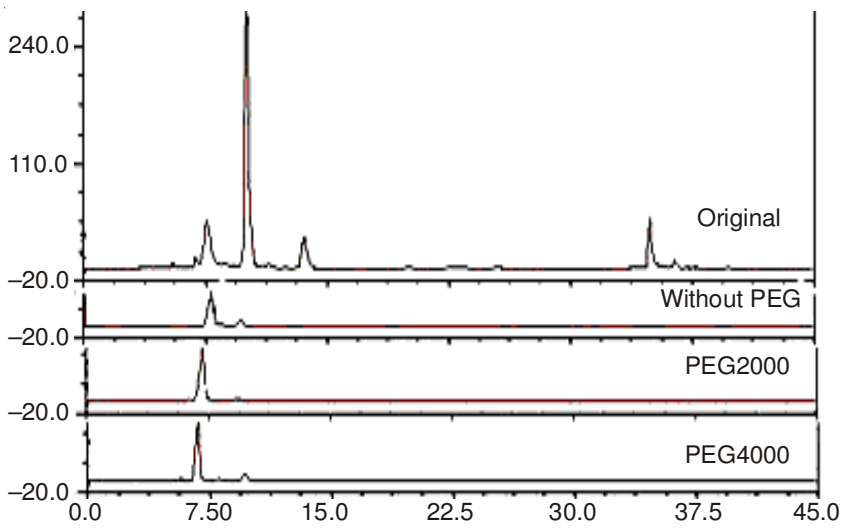

Fig. 2. Results of compound $\mathbf{1}$ in light phase of different PEG systems

By experiment, it shows that the low polar component (impurity) almost was not extracted into organic phase in this operation even in control test. It indicated that the components which have more oleophilic property can interact with high polar comments and keep in aqueous phase. When PEG was used in partition system, low polarity components had other more interaction and enhanced them stayed in aqueous phase, which made the low polarity impurity did not partition into organic phase. The higher polar component 1 interacted weakly with PEG and other components in this partition system, which made component $\mathbf{1}$ extract more easily by organic phase.

Results showed the effects on variant polyethylene glycols (PEG-2000, 4000, 6000, 10000, 20000, 1 \% weight in water solution) on targeted partition for separation of compound 2 are different. The residue was partitioned in other aqueous PEGs- PE systems after compound 1 was separated. Extraction ratio $(\mathrm{E})$ were $0.25,0.24,0.26,0.21$ and 0.23 related to PEG2000, $-4000,-6000,-10000$ and -20000 system respectively (E 0.15 to control test) meanwhile partition coefficient $(\mathrm{K})$ were $0.51,0.46,0.63,0.42$ and 0.57 related to PEG-2000, $-4000,-6000,-10000$ and -20000 system, respectively (K 0.20 to control test). PEG-2000 gave a more pure compound $\mathbf{2}$, whose result is presented in Fig. 3.

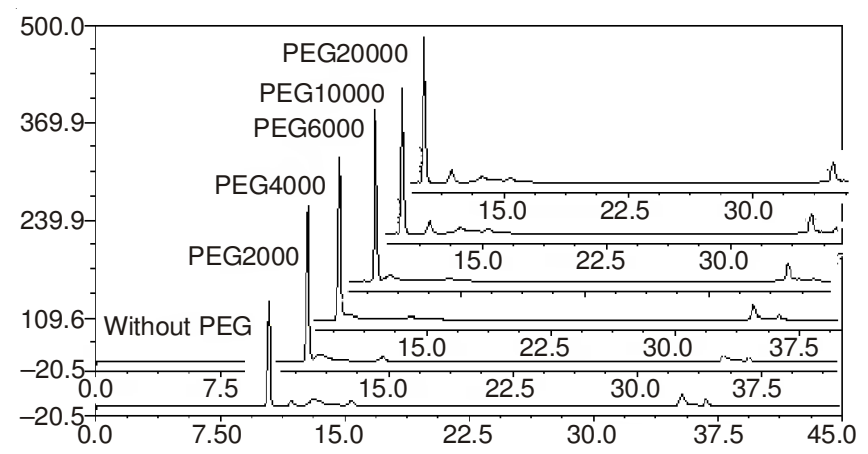

Fig. 3. Results of compound $\mathbf{2}$ in light phase of different PEG systems 
When molecular weight of PEG increases, extraction yield of compound $\mathbf{2}$ increases, meanwhile purity decreases (Fig. 4). Low molecular weight of PEG increased selectivity of extraction.

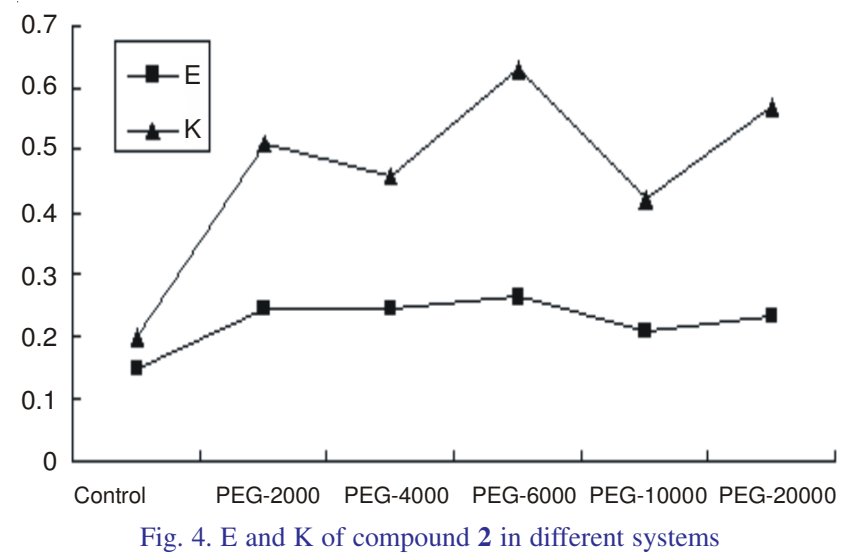

At PEG systems which have same mass concentration, lower molecular weight PEG means higher molecular concentration in water phase and interaction between polymer and components is stronger. This leads extraction have property of selectivity. When higher molecular weight PEG systems are used, viscosity of water solution increases, meanwhile the extraction processing is more difficult.

Effects of partition system on selective separation of compound 2 and the impurity: Fig. 5 showed ratio of relative concentration of compound 2 to the impurity (A2/A3) decreased from 6.96 for PEG-2000 to 5.78, 4.75, 4.29, 4.26 for PEG4000, -6000, -10000 and -20000 partition systems respectively, meanwhile 3.06 for non PEG partition system and 10.40 for starting solution. With the increasing of the molecular weight of PEG, the ratio decreases. It means that in same amount of PEG in water solution (1\%), low molecular weight PEG has more advantages than the higher molecular PEGs; because in the same mass concentration of PEG solutions, higher molecular weight means lower molecular concentration and weaker interaction between PEG and components. It made extraction have less property of selectivity. PEG-2000 system provide strongest selectivity on extraction processes related on separation of compound $\mathbf{2}$ and the impurity, when same mass concentration of PEG systems was used.

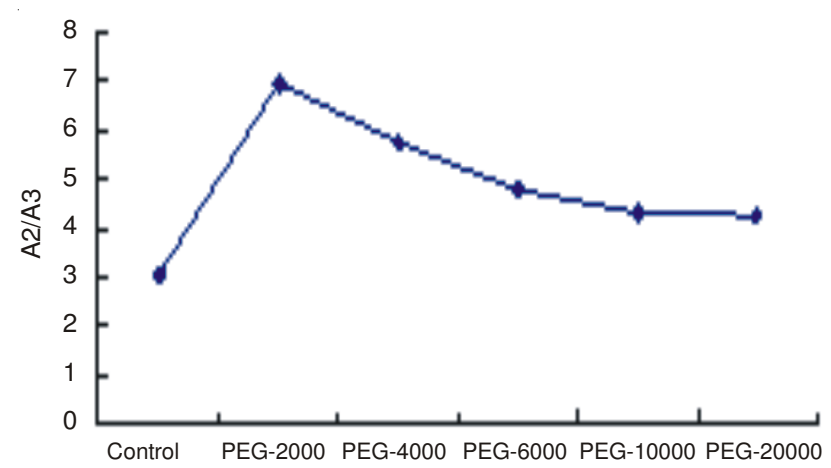

Fig. 5. Ratio of relative concentration of compound 2 and the impurity in light phase

\section{Conclusion}

Targeted partition in liquid two-phase system was successful in separation of components from gardenia yellow. When a target partition reagent introduced into partition system, the separation showed obviously selectivity. In this partition system, a lower polarity component was more difficult to be partition in organic and extracted. Therefore, the polar compound $\mathbf{1}$ was separated firstly and then compound $\mathbf{2}$ was following. In these partition systems, a lower molecular weight polymer, PEG-2000 has advantage for selectively separation of components.

\section{ACKNOWLEDGEMENTS}

This work was financially supported by the National Natural Science Foundation of China (No. 81060261), Natural Science Foundation of Guangxi Province, China (No. 2011jjD20002) and Science Research and Technology Development Foundation of Guagnxi Province, China (No.11107009-3-5).

\section{REFERENCES}

1. A. Ozaki, M. Kitano, N. Furusawa, H. Yamaguchi, K. Kuroda and G. Endo, Food Chem. Toxicol., 40, 1603 (2002).

2. R.A.A. Lelono, S. Tachibana and K. Itoh, Pak. J. Biol. Sci., 12, 949 (2009).

3. B. Yang, X. Liu and Y.X. Gao, Nnov. Food Sci. Emerg., 10, 610 (2009).

4. M. Carmona, A. Zalacain, A.M. Sanchez, J.L. Novella and G.L. Alonso, J. Agric. Food Chem., 54, 973 (2006).

5. Y.Q. Zheng, J.X. Liu, J.N. Wang and L. Xu, Brain Res., 1138, 86 (2007).

6. K.N. Nam, Y.M. Park, H.J. Jung, J.Y. Lee, B.D. Min, S.-U. Park, W.-S. Jung, K.-H. Cho, J.-H. Park, I. Kang, J.-W. Hong and E.H. Lee, Eur. J. Pharmacol., 648, 110 (2010).

7. Y. Chen, H. Zhang, X. Tian, C. Zhao, L. Cai, Y. Liu, L. Jia, H.-X. Yin and C. Chen, Food Chem., 109, 484 (2008).

8. T.Q. Pham, F. Cormier, E. Farnworth, V.H. Tong and M.-R. Van Calsteren, J. Agric. Food Chem., 48, 1455 (2000).

9. B. Ghadrdoost, A.A. Vafaei, A. Rashidy-Pour, R. Hajisoltani, A.R. Bandegi, F. Motamedi, S. Haghighi, H.R. Sameni and S. Pahlvan, Eur. J. Pharmacol., 667, 222 (2011).

10. T. Debnath, P.-J. Park, N.C. Deb Nath, N.B. Samad, H.W. Park and B.O. Lim, Food Chem., 128, 697 (2011).

11. L. Sheng, Z.Y. Qian, S.G. Zheng and L. Xi, Eur. J. Pharmacol., 543, 116 (2006).

12. S.S. Maysam, B.S. Zahra and H. Heydarzadel, Clin. Biochem., 44, S27 (2011).

13. S. Soeda, T. Ochiai, L. Paopong, H. Tanaka, Y. Shoyama and H. Shimeno, Life Sci., 69, 2887 (2001).

14. M.M. Xu, Q. Sun, J. Su, J.F. Wang, C. Xu, T. Zhang and Q.L. Sun, Enzyme Microb. Technol., 42, 440 (2008).

15. M. Scordino, A. Di Mauro, A. Passerini and E. Maccarone, J. Agric. Food Chem., 52, 1965 (2004).

16. C.P. Wang, J.B. Ji, L.H. Wang and T.H. Pao, Chem. Ind. Eng. Prog., 22, 622 (2003).

17. Y.Y. Li and Y.X. Gao, J. Food Sci., 27, 113 (2006)

18. J.F. Chen, G.M. Fu, Y. Wan, C.M. Liu, J.X. Chai, H.G. Li, J.T. Wang, M. Hu and L.N. Zhang, J. Chromatogr. B, 893-894, 43 (2012).

19. W.D. Conway, in ed.: R.J. Petroski, Modern Countercurrent Chromatography, ACS Symposium Series, American Chemical Society: Washington, DC, p. 92 (1995).

20. S.A. Mohajeri, H. Hosseinzadeh, F. Keyhanfar and J. Aghamohammadian, J. Sep. Sci., 33, 2302 (2010).

21. M.R.V. Calsteren and M.C. Biseannetle, J. Agric. Food Chem., 45, 1055 (1997).

22. A. Ozaki, M. Kitano, N. Furusawa, H. Yamaguchi, K. Kuroda and G. Endo, Food Chem. Toxicol., 40, 1603 (2002).

23. Y. Yu, X.L. Feng, H. Gao, Z.L. Xie, Y. Dai, X.J. Huang, H. Kurihara, W.C. Ye, Y. Zhong and X.S. Yao, Fitoterapia, 83, 563 (2012).

24. H.J. Choi, Y.S. Park, M.G. Kim,v T.K. Kim, N.S. Yoon and Y.J. Lim, Dyes Pigments, 49, 15 (2001). 